\title{
Effect of an Educational Booklet on Knowledge and Attitude Regarding Major Depressive Disorder in Medical Students in Delhi
}

Medha Goyal', Charu Kohli', Jugal Kishore', Ram C. Jiloha'.

\begin{abstract}
.
Background: Depression is one of the most common mental disorders affecting people in the world. It is also a growing concern in younger population particularly medical students. There are many pharmaceutical interventions for treatment of depression but there is paucity of data to determine the effect of educational intervention on the knowledge, attitude and help seeking behaviour regarding depression among medical students. Methods: An interventional study was carried out among randomly selected 100 medical students except interns over a period of 6 months from March-August 2011 in a medical college in Delhi to assess the effect of educational booklet on knowledge and attitude about depression. Data was collected using pre-tested questionnaire and analyzed using SPSS version 16 software. Statistical significance in pre and post intervention proportions was determined using Mc Nemar test (MN) and for other proportions Chi-square test. Results: The study shown that only $71 \%$ of subjects knew that depression is a disease in pre intervention phase, which rose to $88 \%$ in post intervention phase $(p=0.01)$. Knowledge of symptoms and treatment significantly improved such as trouble falling asleep or too much sleep ( $p=0.03$ ), feeling tired or decreased energy ( $M N=17.6, p=0.01$ ), feeling bad about self $(M N=21.8, p=0.01)$, speaking slowly other can notice ( $M N=19.1, p=0.01$ ) and can be treated by improving awareness $(M N=8.6, p=0.03)$, and anti-depressants do not cause much of side effects $(M N=17.3, p=0.01)$. Most common reasons for not seeking help were thinking that there is lack of understanding by other people about the depression (63\%), lack of confidentiality ( $49 \%$ ), social stigma (30\%), fear of rejection (26\%) and time constraints $(6 \%)$. Majority of students accepted the booklet for their understanding about depression where $63 \%$ considered that it improved their knowledge to great extent. Conclusions: Educational interventional booklet should be promoted at bigger level to help students to identify and understand the depression which may improve health seeking behavior and could decrease their suffering if they fall sick.
\end{abstract}

Keywords: Depressive Disorder; Pamphlets; Health Knowledge, Attitudes, Practice; Students, Medical (Source: MeSH, NLM).

About the Author Medha Goyal is currently fourth year medical student of Maulana Azad Medical College in New Delhi, India. She is also a recipient of Indian Council of Medical Research (ICMR) student fellowship.
Submission: 2012, May 15 Accepted: 2012, July 19.

Process: Peer-Reviewed.

\section{Introduction.}

Depression is one of the most common mental disorders affecting 121 million people in the world. It presents with depressed mood, loss of interest or pleasure, feelings of guilt or low self-worth, disturbed sleep or appetite, low energy and poor concentration., ${ }^{1,2}$ Presently, depression is already the 2nd cause of DALYS in the age category 15 44 years for both sexes combined. By the year 2020, depression is projected to reach 2nd place of the ranking of DALYs (Disability Adjusted Life Years) loss calculated for all ages, both sexes.' The lifetime prevalence of depression is $12.1 \% .^{3}$ It accounts for $5 \%$ of total burden of disease from all causes in the world. ${ }^{4}$ The prevalence of depression is variable in different age groups and occupation. In South Asia, 14,582 thousand DALY's loss due to depression which is $3.6 \%$ of all causes. ${ }^{5} \mathrm{~A}$ large population-based study from
South India reported overall prevalence of depression to be $15.1 \%$ after adjusting for age using the 2001 census data. ${ }^{6}$

Medical students are highly prone to stress, anxiety and depression as they confront significant academic, psychological and existential stressors throughout their training. ${ }^{7-10}$ Studies have shown that level of depression is very high in medical students as compared to the general population." Depression is associated with suicides and it was found that $53.6 \%$ of the medical students have suicidal ideation and $4.9 \%$ have contemplated suicide. ${ }^{12}$

In an intervention study in the University of Hawaii among medical students, $59.1 \%$ of them had reported depressive symptoms and $30.2 \%$ reported suicidal ideation. ${ }^{13}$ An In-

${ }^{1}$ Maulana Azad Medical College, New Delhi, India.

Correspondence

Dr. Charu Kohli.

Address: Department of Community Medicine, Maulana Azad Medical College, New Delhi 110002, India.

E.mail: kohlicdoc17@gmail.com 
dian study showed overall level of depression in medical students to be as high as $39.44 \% .{ }^{14} \mathrm{~A}$ big hurdle encountered while dealing with depression in medical students is that very few of them seek help although depression is reliably diagnosed and many treatment options are available. ${ }^{15}$ However, there are very few studies conducted among Indian medical students to assess the impact of an educational intervention on the knowledge, attitude and help seeking behaviour regarding depression.

Therefore this study was planned with an objective to assess the impact of Information Educational Communication (IEC) material in the form of a booklet on knowledge, attitude and approach to deal with depression among medical students in Delhi.

\section{Methods. \\ Study design, participants and sampling technique}

A college based intervention study was conducted over a period of 6 months from March-August 2011 in a medical college of Delhi. Sample size was calculated on the basis of a study that the baseline knowledge about depression in medical students to be $50 \%{ }^{16}$ It was expected to moderately increase up to $70 \%$ after intervention in the form of an educational booklet. Taking power of the study to be $80 \%$ and $\alpha$ error $5 \%$, sample size was calculated using EPIINFO software version 3.3.2. It came out to be 103. However, 105 medical students from different batches were selected by stratified sampling from their roll numbers. Out of 105 students enrolled, 5 students did not reported back with completed questionnaire after 1 week in spite of three reminders. Therefore only 100 students were included in the final analysis.

\section{Methodology}

The study was divided into three phases; pre intervention phase, intervention phase and post intervention phase. In pre intervention phase, selected students were given a self administered questionnaire. In intervention phase, students were given intervention material in form of an IEC booklet. In post intervention phase, the same students were contacted a week after giving IEC booklet. The students were again asked to fill the questionnaire. Comparison was made on the basis of response to questionnaire before and after the intervention.

\section{Inclusion and exclusion criteria}

All undergraduate medical students enrolled with medical college were included. The students doing internship were excluded. None of the student was seriously ill due to physical component of health or admitted in hospital.

\section{Study tool}

For assessing knowledge and attitude, a semi-structure questionnaire consisting of items on age, current semester of study, family type, parent's occupation, history of previous schooling and interest in pursuing medical course along with student's knowledge, attitude and perception about causes, symptoms, treatment of depression and their help seeking behavior in case they suffered from depression was prepared. The majority of items of questionnaire were based on validated instrument, ${ }^{17,18}$ however it was tested for its feasibility and appropriateness among medical students aged 18-25 years of another medical college in Delhi.

For intervention, an IEC booklet containing information regarding various aspects of depression like symptoms, causes, risk factors, different forms, treatment options, common myths and easy techniques that could be tried prior to taking professional help, in case the student suffered from depression was developed. The content of IEC booklet was based on the standard textbook of psychiatry ${ }^{19}$ and was approved by professional psychiatrist and public health expert. It was pretested among students of same age group who were not a part of study sample. Their suggestions were incorporated in the booklet before use in the actual study. The booklet was printed in simple language and made colorful and attractive with all major issues related to depression were dealt with.

\section{Statistical analysis}

The data collected was entered in MS-Excel and analyzed using SPSS software. Results were presented in simple proportions and difference between groups was assessed for their significance using statistical tests. For comparison of pre and post intervention difference, Mc Nemar test was applied while aspects, which were evaluated only once but compared with other group, their significance was assessed using chi-square test. The results were accepted as significant if " $p$ " value was less than 0.05 .

\section{Ethical issues}

The students were explained the purpose of the study. Information collected and identity was kept confidential and their informed consent was taken before taking information. The study was approved by the institutional ethical committee.

\section{Results.}

Out of 100 medical students who participated in the study, with a mean age of $20 \pm 1.28$ years old and 48 were males. Sixty-four percent were hostellers and $36 \%$ were day scholars; $81 \%$ stated that they are pursuing medical career with self interest while $8 \%$ said parent's interest is the reason behind opting this profession.

\section{Knowledge about causes and risk factors}

It was found in the study that $71 \%$ of students knew that depression is a disease in pre intervention phase however, this figure rose to $88 \%$ in post intervention phase. This increase was found to be statistically significant $(p=0.01)$. The 
students who considered that old people and women are less prone to suffer from depression fell from $11 \%$ to $9 \%$ and $8 \%$ to $2 \%$ respectively after intervention.

Children do not suffer from depression was initially considered by $16 \%$ students and after intervention by $12 \%$ students. The percentage of students who felt that lower socio-economic status increases the risk of developing depression increased after the study from initial $50 \%$ to $67 \%$, which was not significant, but the students who considered that people in contact with depressed people tend to develop odd or strange behavior decreased significantly after the intervention from $43 \%$ to $21 \%(p=0.01) .57 \%$ of students thought that higher education or high Intelligent Quotient (IQ) increases the risk of developing depression in post intervention phase as compared to $41 \%$ in pre intervention phase which is statistically significant $(p=0.03) .97 \%$ of the subjects knew that depression is a result of dynamic imbalance of brain neurotransmitter after intervention as compared to $84 \%$ before intervention $(p=0.04)$.

Similarly, there was a significant increase in the number of students who thought that depression results from abnormal family structure from $81 \%$ to $92 \%$ after intervention $(p=0.03)$. Depression could be due to social circumstances was considered prior to intervention by $97 \%$ students which improved to $99 \%$ after intervention. There was an increase in percentage of students who considered poor nutritive diet, polluted air, loss of semen/vaginal secretion and god punishing for sins or wrong doing as cause of depression from initial $43 \%, 25 \%, 27 \%$ and $16 \%$ respectively to $74 \%$, $59 \%, 63 \%$ and $38 \%$ respectively after intervention. Achievement oriented society was taken as cause of depression before intervention by $82 \%$ and after intervention by $91 \%$ of students $(p=0.10)$. The fact that depression runs in family was known initially to only $44 \%$ students while after intervention, it was known to $75 \%$ (Table 1).

\section{Knowledge about symptoms of depression}

In regard to symptoms of depression, it was observed that $95 \%$ students knew that decreased pleasure or interest in doing things was a symptom in post intervention phase vis-a vis $86 \%$ in pre intervention phase $(p=0.49)$. Similarly, feeling down or hopelessness was mentioned as a symptom of depression by $94 \%$ students, which after intervention increased to $99 \%(p=0.12)$. After the intervention, trouble falling sleep or sleeping too much was considered as symptom of depression by $96 \%$ as against earlier by $86 \%(p=0.03)$. There was an increase from $69 \%$ to $96 \%$ in the number of students who considered feeling tired or having decreased energy as symptom of depression after intervention $(p=0.01)$.

Poor appetite or overeating was thought as a symptom before intervention by $79 \%$ and after intervention by $98 \%$ respondents $(p=0.01)$. Initially $92 \%$ students responded to "feeling bad about yourself or that you are a failure or has let yourself or your family down?" as a symptom of depression, which post intervention reached $100 \%(p=0.01)$. Prior to intervention, $76 \%$ students believed that trouble concentrating on activities, such as reading newspaper or watching television was a symptom of depression, which after intervention was known to $95 \%$ students $(p=0.01)$.

A significant increase was detected in the number of students from $59 \%$ to $89 \%$ who considered "moving or speaking so slowly that other people have noticed or being fidgety or restless" as a symptom $(p=0.01)$. After the intervention, $98 \%$ pointed out the thoughts of being dead or hurting themselves in some way as a symptom against initial $84 \%(p=0.01)$ as shown in the Table 2 .

\section{Knowledge about treatment of depression}

Regarding treatment of depression, there was a slight decrease in the number of students who considered depression as untreatable, from $4 \%$ to $3 \%$ after intervention. Similarly, the percentage of students who considered that depression was as well treated by spiritual and faith healers as the psychiatrists decreased from $43 \%$ to $35 \%$ in post intervention but the decrease is not statistically significant $(p=0.29)$. The percentage of students who believed that depression can be treated by improving the awareness of patient towards his emotional feelings improved significantly from $78 \%$ to $94 \%(p=0.03)$. Comparing the response on question whether taking anti-depressants has side effects showed improvement when $92 \%$ students thought that taking anti-depressants has side effects, which declined to $66 \%$ after intervention $(p=0.01)$. Similarly, there was but not significant decrease in the percentage of students who thought that anti-depressants are addictive from $51 \%$ to $45 \%$ in post intervention phase $(p=0.48)$. (Table 3$)$

\section{Attitude towards depression}

Initially, $79 \%$ subjects believed that they would employ a person who had recovered from depression and after the intervention it increased to $89 \%(p=0.07)$. The percentage of students who would be against a close relative marrying a person who has recovered from depression after the study increased from $17 \%$ to $24 \%(p=0.20)$ but the difference is not significant statistically. The students who found themselves comfortable talking with depressed person significantly improved after the intervention from $58 \%$ to $73 \%$ ( $p=$ 0.04 ). The results of attitude toward depression are depicted in Table 4.

\section{Help seeking behavior}

Items on help seeking behavior were asked before distribution of booklet only. It was because of not to identify medical students with depression for social and ethical concerns. However, they were advised to report to psychiatry OPD if they had symptoms suggestive of depression. 
Table 1. Comparison of pre and post intervention phases on knowledge about causes and risk factors of depression.

\begin{tabular}{|c|c|c|c|c|}
\hline Items & $\begin{array}{l}\text { Pre - Interven- } \\
\quad \text { tion }(\%)\end{array}$ & $\begin{array}{l}\text { Post - Inter- } \\
\text { vention }(\%)\end{array}$ & Mc Nemar test & $\mathrm{p}$ Value \\
\hline Depression is a disease & 71 & 88 & - & 0.01 \\
\hline Older people are less prone to depression & 11 & 9 & - & 0.80 \\
\hline Children don't suffer from depression & 16 & 12 & - & 0.50 \\
\hline Women are less prone to depression & 8 & 2 & - & 0.10 \\
\hline $\begin{array}{l}\text { People in contact with depressed people develop strange } \\
\text { behavior }\end{array}$ & 43 & 21 & 11.02 & 0.01 \\
\hline Lower socio-economic class is more prone to depression & 50 & 67 & 5.68 & 0.17 \\
\hline High IQ is a risk factor for developing depression & 41 & 57 & 4.32 & 0.03 \\
\hline \multicolumn{5}{|l|}{ Depression is caused by } \\
\hline Imbalance of brain neurotransmitter & 84 & 97 & - & 0.04 \\
\hline Abnormal family structure & 81 & 92 & - & 0.03 \\
\hline Social circumstances & 97 & 99 & - & 0.62 \\
\hline Poor nutritive diet & 43 & 74 & 17.64 & 0.01 \\
\hline Polluted air & 25 & 59 & 20.94 & 0.01 \\
\hline Loss of semen/vaginal fluid & 27 & 63 & 21.8 & - \\
\hline God punishing for wrong doing/sins & 16 & 38 & 9.5 & 0.02 \\
\hline Achievement oriented society & 82 & 91 & - & 0.10 \\
\hline Depression runs in family & 44 & 75 & 15.78 & - \\
\hline
\end{tabular}

Table 2. Comparison of pre and post intervention phases on knowledge about symptoms of depression.

\begin{tabular}{|c|c|c|c|c|}
\hline Items & $\begin{array}{l}\text { Pre - Interven- } \\
\quad \text { tion (\%) }\end{array}$ & $\begin{array}{l}\text { Post - Inter- } \\
\text { vention (\%) }\end{array}$ & Mc Nemar test & $\mathrm{p}$ Value \\
\hline Decreased pleasure or interest in doing things? & 86 & 95 & - & 0.49 \\
\hline Feeling down or hopeless? & 94 & 99 & - & 0.12 \\
\hline Trouble falling/staying asleep, sleeping too much? & 86 & 96 & - & 0.03 \\
\hline Poor appetite or overeating? & 79 & 98 & - & 0.01 \\
\hline $\begin{array}{l}\text { Feeling bad about yourself or that you are a failure or } \\
\text { has let yourself or your family down? }\end{array}$ & 92 & 100 & 21.87 & 0.01 \\
\hline $\begin{array}{l}\text { Trouble concentrating on things, such as reading newspa- } \\
\text { per or watching television? }\end{array}$ & 76 & 95 & - & 0.01 \\
\hline $\begin{array}{l}\text { Thoughts that you would be better off dead or of hurting } \\
\text { yourself in some way? }\end{array}$ & 84 & 98 & - & 0.01 \\
\hline
\end{tabular}

Table 3. Knowledge about treatment of depression in pre and post intervention phases.

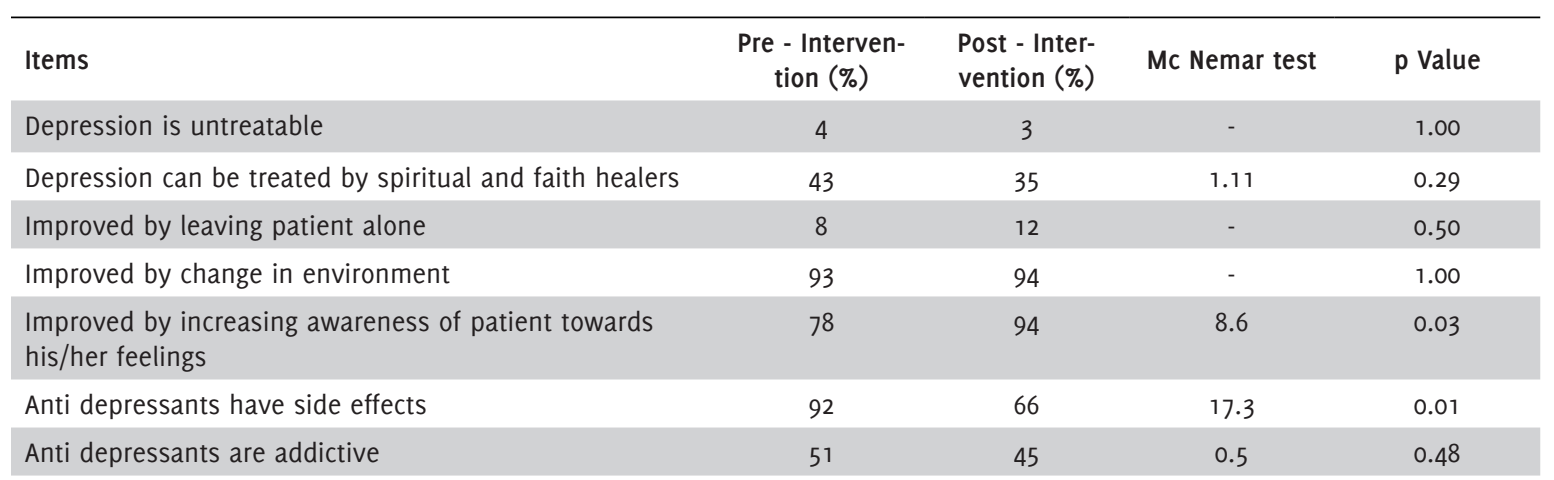


Therefore items on health seeking were not assessed in post intervention phase. On asking whom they would prefer to consult if they suffer from depression, $73 \%$ students stated that they would like to seek help from a health professional like a counselor or a psychotherapist. $72 \%$ said they would like to discuss with their family members, $35 \%$ would prefer in taking help from teachers and mentors. $26 \%$ students thought that self treatment would be best for them while $20 \%$ would like to seek information from internet.

Another significant observation was reasons for not seeking help in depression. $19 \%$ of the students felt that if they go to anybody for help, be it their family members, health professionals or teachers, it would not yield any result. Another $9 \%$ felt ashamed while asking for help and a same percentage felt that time constraint is responsible for not seeking help. When asked about the problems faced while seeking help, $63 \%$ believed that the lack of understanding by other people prevent them from taking help. As many as $49 \%$ students said that greatest fear while seeking help was the lack of confidentiality. Other reasons were stigma $(30 \%)$, fear of rejection $(26 \%)$ and waste of their time $(6 \%)$ as shown in Figure 1.

The various mediums preferred by students for seeking help were determined and it was noticed that $80 \%$ preferred face-to-face interview followed by telephone $(22 \%)$, internet $(17 \%)$ and letter writing $(14 \%)$.

Figure 1. Greatest fear reported by study subjects for not seeking help.

\section{Greatest fear while seeking help}

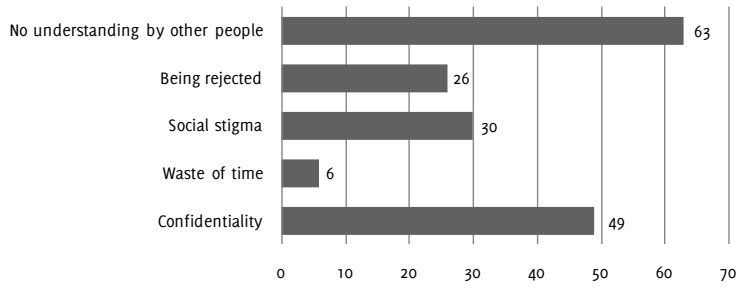

Figure 2. Acceptability of IEC booklet by study subjects.

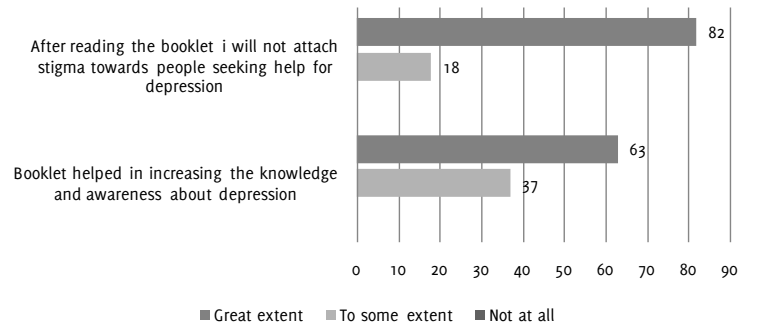

\section{Acceptability of intervention booklet}

Feedback to determine acceptability of booklet was obtained. As many as $63 \%$ students believed that it has increased their knowledge and awareness about depression to a great extent. About $37 \%$ felt that it increased their knowledge to some extent. $82 \%$ believed that they would not attach stigma towards people with depression seeking help but $18 \%$ still thought that they might attach stigma to some extent. The results are displayed in Figure 2.

\section{Discussion.}

Improving knowledge regarding depression needs basic understanding of the students that depression is a disease and needs to be taken care of and not to be left undiagnosed or untreated. Since these issues were addressed in the booklet there was significant improvement in knowledge, attitude and health seeking behavior about depression in students.

The number of students who considered depression a disease increased from $71 \%$ to $88 \%$. Most of the students had high knowledge of the causes of depression like neurotransmitter imbalance, abnormal family structure and social circumstances owing to their medical knowledge. But many of them were not aware of factors like poorly nutritive diet, polluted air, and loss of semen or vaginal secretions as causes of depression. This is consistent with findings observed by Kishore et al where it was stated that very small percentage of medical practitioners knew about these causes of mental disorders. ${ }^{20}$ It reflects general lack of emphasis on these factors by medical professionals also. The genetic link to depression is an important factor as it helps students to detect depression early in patients with a family history, which was included in the booklet. Few responses in post intervention had gone against the expected finding. For example, there was an increase in the number of students who believed that depression may result due to god punishing them for wrong doing or sins. This could be due to prevalent myths even among medical professionals. Another explanation for this could be that since this intervention was carried out for a short duration only, a person's deep rooted beliefs become stronger in such circumstances. Similar findings of myths and wrong beliefs were reported by Kishore et al. ${ }^{20}$ Similar findings on etiology of psychiatric illnesses was reported by a study conducted among medical students by Chawla et al in which excessive emotions, loneliness, past sins and evil spirits were consi-

Table 4. Attitude regarding depression among study subjects.

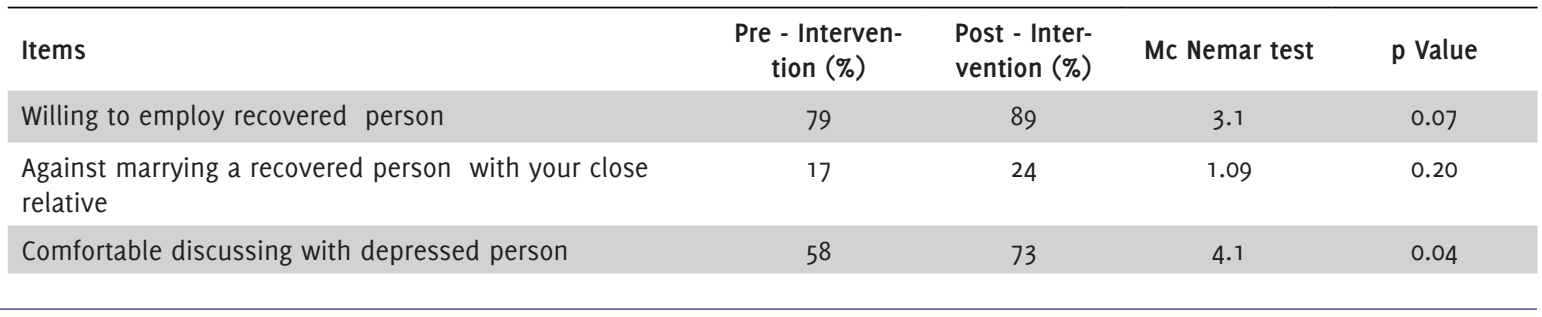


dered as a cause of psychiatric disorders. ${ }^{21}$ It reflects lack of emphasis on these factors in medical teaching as well.

The slight increase in percentage of students who believed that lower socio-economic status increases the risk of developing depression could be due to the fact that they considered lack of resources could result in poorly nutritive diet and polluted housing conditions, which are in turn considered as risk factors for depression. This is consistent with the study carried out among medical professionals in which according to $63 \%$ respondents, mental disorders were caused solely by unfavorable social circumstances. ${ }^{20}$

Students were made aware of all the symptoms that could point towards depressive behavior. About $70 \%$ students were already aware of the symptoms, which after reading the booklet increased strikingly to $90 \%$ in most cases. Identifying these symptoms by the students, which may otherwise appear as general irritable mood swings, for more than 2 weeks in general, can help the students to seek early help. The findings are consistent with the results of a study carried out among Australian medical students in which being sad, down or miserable was stated as a symptom of depression by $71 \%$ second year students and $82 \%$ of fourth year students. Others symptoms reported were sleep disturbances, being unhappy or depressed, feeling tired all the time, easy fatigability etc. ${ }^{22}$

Most of the students were already aware of the treatment available for depression. There was also a detectable decrease from $43 \%$ to $35 \%$ in the number of students who believed that depression could be treated by faith healers as well. This is important because it represents that depression is not merely a disease that can be improved by gaining faith but is an abnormal condition with a determinable cause and proper treatment available. However, similar views were expressed by medical professionals regarding faith healer ability to treat mental disorders in another study. In that study $8 \%$ of the respondents considered mental illness to be untreatable. ${ }^{20}$

A notable increase from $78 \%$ to $94 \%$ was detected in number of students who believed that depression can be improved by increasing the awareness of patient towards his feeling. This is important as mostly medical students ward off these feeling as normal emotional response to medical school, so making them aware of their feelings will help them realize that they could be depressed and should seek help. Students need to be made aware of the fact that taking anti-depressant is like taking other medications. The stigma attached to taking anti-depressant medication need to be addressed. After reading the booklet there was a noteworthy fall from $92 \%$ to $66 \%$ students who believed that taking them had side effects. Side effects involved with them are general side effects but not troublesome enough that the medication can't be taken. It is important to remove misconceptions of students regarding anti-depressants because it could be hindering them to seek help from psychiatric expert.

The attitude of medical students towards depressed individuals was evaluated as it may have repercussions on their future practice and development of intolerance towards depressed individuals. This was also shown by a study conducted among 40 general practitioners (CPS) in Liverpool and Manchester who completed the Depression Attitude Questionnaire (DAQ) and were asked for prescribing information. The ability of GPS to identify depression may not be an independent variable, but may rather reflect other beliefs, attitudes and skills. This has considerable implications for educational interventions in primary care. ${ }^{23}$ Hence questions on various issues like employing an individual who has recovered or marriage of a relative with a person having history of depression or the ability to feel comfortable while talking with depressed person were included in the questionnaire.

Considerable improvements were noted in the above questions. However surprisingly, after the study there was a slight increase in number of individuals who would be against marriage to a recovered individual. The basis of this finding could be that after reading the booklet more people became aware of the fact that depression can run in families and thus some preferred not to marry an individual who have recovered from depression. Cenetic linkage to depression was told in the booklet, which could be a reason for such attitude.

An important finding was observed in a previous study in the same college that only $4.7 \%$ students had ever consulted a counselor even though around $14.7 \%$ admitted to have had past depressive episodes. ${ }^{15}$ This makes it critical to determine the various aspects of help seeking behavior in students. Most of that students preferred professional counselors $(73 \%)$ to seek help, this makes counseling an important tool to counteract increasing depression. Similar results were reported by another study where $54 \%$ of first year students and $46 \%$ of second year medical students preferred counseling. ${ }^{22}$ The medium that was mostly favored by students was face-to-face interview $(80 \%)$. This could be probably due to the ease with which they are able to communicate in the interview, including clarifying their queries.

The main reasons for their not so forthcoming approach in regard to seeking help were also cited. It was found that mostly they felt that nobody could help them (19\%) and a few felt ashamed ( $9 \%$ ) while seeking help. The main problems faced while seeking help were detected in which no understanding by others was cited as the most common reason (63\%) followed by lack of confidentiality of the treatment, fear of documentation of their illness, social stigma $(30 \%)$ and being rejected by others $(26 \%)$ and waste 
of time $(6 \%)$ were other reasons. This is consistent with findings of a study conducted in University of California in which the most frequently cited barriers to using these services were determined as lack of time, confidentiality and social stigma. ${ }^{24}$ Since social stigma turned out to be a big factor in both the studies, this issue was specifically addressed in the booklet. After reading the booklet, $82 \%$ believed that they would not attach stigma but $18 \%$ still considered that they might attach stigma to some extent. This can be due to already high prevalence of social stigma in medical students and should be further brought down by counseling. Better interaction with faculty, advisory services and counseling services have been reported to help students to deal with stress and depression according to a study conducted by Shaikh et al in Pakistan Medical School. ${ }^{25}$ Thus, knowledge and attitude of students towards depression was found to improve following the educational intervention in the form of IEC booklet.

This is in accord with the fact that most of the students accepted the booklet and $63 \%$ found that it increased their knowledge about depression to a great extent and $37 \%$ considered that it increased to some extent. The positive feedback obtained is consistent with other studies, which have used other methods of intervention. ${ }^{26-29}$

The study has following limitations: a) the study was confined to only one medical college which limit the generalizability to all medical students. b) Intervention in form of booklet was applied to all students and had no comparative group. Therefore the causal effect of booklet on improvement of knowledge, attitude and practice cannot be stated. c) Long term effect of the booklet could not be assessed.

The study draws conclusion that intervention in the form of booklet had profound improvement in the knowledge of students regarding various aspects of depression such as risk factors, causes, symptoms and treatment. They will attached less stigma to the depression and favorable to work with mentally ill subject. The various myths like antidepressants having a lot of side effects and being addictive were attended to. Thus IEC booklet is effective tool to bring change in their behavior for seeking help for depression if they fall sick.

\section{References.}

1. WHO 2012. Mental Health: Depression. Available from http://www.who. int/mental_health/management/depression/definition/en/

2. WHO 2011. Mental health: a state of well-being. Geneva: WHO. Available from http://www.who.int/features/factfiles/mental_health/en/index. html.

3. Andrade L, Caraveo-Anduaga JJ, Berglund P, Bijl RV, De Graaf R, Vollebergh $W$ et al 2003. The epidemiology of major depressive episodes: results from the International Consortium of Psychiatric Epidemiology (ICPE) Surveys. Int J Meth Psy Res. 12(1):3-21.

4. Lopez A, Mathers C, Ezzati M, Jamison D, Murray C 2006. Global burden of disease and risk factors. Washington DC, Oxford University Press and World Bank.

5. Patel V 1999. The epidemiology of Common Mental Disorders in South Asia. NIMHANS Journal. 17: 307-327.

6. Poongothai $S$ et al 2009. Prevalence of depression in a large urban South Indian population - The Chennai Urban Rural Epidemiology Study (CURES-70). plos One. 4(9): e7185.

7. Niemi PM, Vainiomaki PT 2006. Medical students' distress--quality, continuity and gender differences during a six-year medical programme. Med Teac. 28:136-141.

8. Dyrbye LN, Thomas MR, Shanafelt TD 2006. Systematic review of depression, anxiety, and other indicators of psychological distress among U.S. and Canadian medical students. Acad Med. 81:354-373.

9. Dahlin M, Joneborg N, Runeson B 2005. Stress and depression among medical students: a cross-sectional study. Med Educ. 39: 594-604.

10. Firth-Cozens J 1989. Stress in medical undergraduates and house officers. Bri J Hosp Med. 41: 161-164.

11. Rosal MC et al 1997. A longitudinal study of student's depression at one medical school. Acad Med. 72: 542-546.

12. Coyal A, Kishore J, Anand T, Rathi A 2012. Suicidal Ideation among medical students in Delhi. J Ment Health Human Behavior . 17 (1): 60-69.

13. Thompson $D$ et al 2010. A program for reducing depressive symptoms and suicidal ideation in medical students. Acad Med J Asso Am Med Col. 85: 1635-1639.

14. Vaidya M, Mulgaonkar K 2007. Prevalence of depression, anxiety and stress in undergraduate medical students and its correlation with their academic performance. Ind J Occu Therap. 39(1): 7-10.

15. Sidana S, Kishore J, Ghosh V, Gulati D, Jiloha RC, Anand T 2012. Depression in students in a medical college in New Delhi: A Cross sectional study. Aus Med J. 5 (5): 247-250.

16. Jafri MA, Minhas FA, Tamiz-Ud-Din A, Slatch MA, Mujeeb F 2011. Knowledge of depression among community members and health care providers in two selected areas of district Rawalpindi. J Col Physicians Surg Pak. 21(12): 756-759.

17. Mukherjee R, Kishore J, Jiloha RC 2006. Attitude towards psychiatry and psychiatric illness among medical professionals. Delhi Psychiatry Society. 9 (1): 34-38.

18. Kishore J, Gupta A, Jiloha RC, Bantman T 2011. Myths, beliefs and perception about mental disorders and health seeking behaviour in Delhi, India. Ind J Psychiatry. 53(4): 324-329.

19. Sadock BJ, Sadock VA. Kaplan Ct Sadock's Comprehensive Textbook of Psychiatry 2(vols). 7 th edition. Philadelphia. Lippincott Williams at Wilkins 2008.

20. Kishore J et al 2007. Beliefs and attitudes towards mental health among health professionals in Delhi. Ind J Commun Med. 32(3): 198-200.

21. Chawla JM et al 2012. Undergraduate medical students' attitude towards psychiatry: A cross sectional study. Ind J Psy. 54:37-40.

22. Hickie I et al 2007. The assessment of depression awareness and helpseeking behaviour: experiences with the International Depression Literacy Survey. BMC Psychiatry. 7(48): 1-12.

23. Dowrick C, Gask L, Perry R, Dixon C, Usherwood T 2000. Do general practitioners' attitudes towards depression predict their clinical behaviour? Psychol Med; 30(2):413-419.

24. Givens JL, Tjia J 2002. Depressed medical students' use of mental health services and barriers to use. Acad Med. $77(9)$ 918-921. 


\section{Original Articles}

25. Shaikh B et al 2004. Students, stress and coping strategies: a case of Pakistani medical school. Educ health. 17(3) 346-353.

26. Thompson D, Goebert D, Takeshita J 2010. A program for reducing depressive symptoms and suicidal ideation in medical students. Acad Med J Assoc Am Med Col. 85:1635-1639.

27. Rong Y, Glozier N, Luscombe GM, Davenport TA, Huang Y, Hickie IB 2011. Improving knowledge and attitudes towards depression: a controlled trial among Chinese medical students. BMC Psychiatry. 8(11):36.

28. Simard AA, Henry M 2009. Impact of a short yoga intervention on medical students' health: a pilot study. Med Teaching. 31(10):950-952.

29. Merritt RK, Price JR, Mollison J, Geddes JR 2007. A cluster randomized controlled trial to assess the effectiveness of an intervention to educate students about depression. Psychol Med. 37(3):363-372.

\section{Acknowledgements}

This project was done as a part of short term studentship received by the first author from the Indian Council of Medical Research (ICMR). The support is greatly acknowledged by the authors.

\section{Conflict of Interest Statement at Funding}

The Authors have no funding, financial relationships or conflicts of interest to disclose.

Cite as:

Goyal M, Kohli C, Kishore J, Jiloha RC. Effect of an Educational Booklet on Knowledge and Attitude Regarding Major Depressive Disorder in Medical Students in Delhi. Int J Med Students 2013;1(1):16-23. 